\title{
Avaliação dos níveis de desgaste e de microdureza em amostras de ferro sinterizado com e sem tratamento de ferroxidação e nitretado a plasma
}

\author{
Evaluation of wear levels and microhardness on sintered iron samples \\ with and without ferrox treatment and submitted to plasma nitriding
}

Marcos Alves Fontes ${ }^{1}$, Ricardo G. Pereira², Frederico A. P. Fernandes ${ }^{2}$, Luiz C. Casteletti ${ }^{2}$, Pedro A. P. Nascente ${ }^{1}$

\section{RESUMO}

A nitretação a plasma consiste numa técnica de modificação superficial que objetiva melhorar algumas propriedades dos materiais, tais como a dureza e resistências ao desgaste e à fadiga. Neste trabalho, este processo foi empregado na modificação superficial de uma liga ferro-cobre sinterizada. Foram realizados ensaios de microdesgaste, do tipo esfera presa, e de microdureza na liga sem tratamento e em amostras submetidas aos tratamentos de ferroxidação e nitretação por plasma, realizados sob diferentes condições de tempo e temperatura. Os resultados indicaram que tanto as resistências ao desgaste como as microdurezas aumentaram com o tempo e a temperatura de nitretação, sendo que a variável que mais influenciou nas características mencionadas foi a temperatura.

Palavras-chave: Nitretação a plasma; Metalurgia do pó; Engenharia de superfície; Microdesgaste; Microdureza.

\begin{abstract}
Plasma nitriding is a surface modification technique used for improving material's mechanical proprieties like hardness, wear resistance, and fatigue resistance. In this work, this process was employed in the surface modification of a sintered ironcopper alloy. Wear, fixed ball type, and microhardness tests were performed on the untreated alloy and on the samples submitted to ferrox treatment and plasma nitriding performed under different conditions of time and temperature. The results showed that both the wear resistance and the microhardness increased with nitriding time and temperature, and the variable which most influenced the aforementioned characteristics was the temperature.
\end{abstract}

Keywords: Plasma nitriding; Powder metallurgy; Surface engineering; Microwear; Microhardness.

1Universidade Federal de São Carlos - Departamento de Engenharia de Materiais - São Carlos (SP) - Brasil

2Universidade de São Paulo - Departamento de Engenharia de Materiais, Aeronáutica e Automobilística (SMM) - São Carlos (SP) - Brasil

Autor correspondente: Marcos A. Fontes - Universidade Federal de São Carlos - Departamento de Engenharia de Materiais - Rodovia Washington Luís (SP-310), Km 235 CEP: 13565-905 - São Carlos (SP) - Brasil 


\section{INTRODUÇÃO}

A demanda por componentes mais resistentes ao desgaste e à corrosão tem promovido um enorme interesse pela engenharia de superfícies, que trabalha e desenvolve processos alternativos de melhoria nas propriedades tribológicas e triboquímicas dos materiais.

A busca por novos aços ou novas ligas sempre foi o caminho mais tradicional de pesquisa para se obter materiais com melhores propriedades mecânicas. Entretanto o custo e o tempo associados a estes desenvolvimentos tornam-se muitas das vezes inadequados pela necessidade e avanço rápido da tecnologia.

A nitretação do ferro e suas ligas, ou de aços, tem sido um assunto de grande importância no contexto de aplicações diversificadas na indústria mecânica, uma vez que o processo de nitretação é responsável pela modificação de propriedades tais como resistência ao desgaste, corrosão e dureza ${ }^{(1)}$. A nitretação é um processo de tratamento termoquímico que envolve a deposição e a difusão de nitrogênio nas superfícies de materiais metálicos. Consiste no endurecimento superficial, pela formação uma camada de nitretos e pela incorporação do nitrogênio, constituindo a camada de difusão ${ }^{(2)}$. O entendimento e o controle da formação da camada nitretada apresenta considerável interesse industrial devido às melhorias alcançadas na resistência ao desgaste, corrosão e resistência à fadiga dos metais e suas ligas.

Entre os diversos processos existentes para a obtenção de melhores propriedades nas superfícies, a técnica de nitretação por plasma permite um melhor controle dos diversos parâmetros envolvidos no processo, acarretando então a formação de uma camada mais bem controlada ${ }^{(2-5)}$.

A dureza e a profundidade da camada de difusão dependem principalmente da quantidade de elementos formadores de nitretos no aço $\mathrm{o}^{(6,7)}$, do tempo e da temperatura do tratamento de nitretação iônica ${ }^{(3,8,9)}$, da composição do gás utilizado no sistema $^{(10)}$ e da microestrutura inicial do material a ser nitretado ${ }^{(11)}$.

Os materiais produzidos pela metalurgia do pó convencional apresentam porosidade residual e por conta disto estão sujeitos ao processo de desgaste mais acentuado em determinadas aplicações. Tratamentos superficiais, como nitretação e nitrocarbonetação, são normalmente usados nestes aços com a finalidade de diminuir o efeito prejudicial dos poros nas propriedades superficiais dos mesmos ${ }^{(12)}$. Neste caso, a presença de uma camada superficial nitretada, com espessura de camada e presença de elementos controlados, é importante para o comportamento tribológico destes materiais $^{(11)}$.

Este trabalho é uma extensão de um artigo recentemente publicado por esta revista ${ }^{(13)}$ e o seu objetivo é promover uma comparação dos níveis de desgaste e valores de dureza, de ligas ferrosas sinterizadas e nitretadas a plasma sob diferentes tempos e temperaturas de tratamento, com amostras submetidas ao tratamento superficial de ferroxidação, como também amostras sem tratamento algum.

\section{PROCEDIMENTO EXPERIMENTAL}

As amostras de ferro sinterizado foram produzidas com partículas de diâmetro na faixa de 20 a $200 \mu \mathrm{m}$ (tamanho médio de $100 \mu \mathrm{m}$ ), com pressão de compactação de $600 \mathrm{MPa}$, obtendo-se desta forma uma densidade a verde aproximada $\left(\rho_{\mathrm{v}}\right)$ de $6,4 \mathrm{~g} / \mathrm{cm}^{3}$, porosidade de $24 \%$, e com as faixas de composições químicas apresentadas na Tabela 1.

Tabela 1.: Faixas de composições químicas da amostra de liga ferrosa.

\begin{tabular}{|c|c|}
\hline Elemento & $\%$ em peso \\
\hline Carbono combinado & $0,20-0,40 \%$ \\
\hline Cobre & $1,75-2,25 \%$ \\
\hline Enxofre & $0,14-0,22 \%$ \\
\hline Ferro & Balanço \\
\hline
\end{tabular}

As amostras foram preparadas inicialmente por meio de lixamento, usando-se progressivamente lixas com granulação referente aos números 220, 320, 400, 500, 600 e 800 e sequencialmente polidas em uma politriz com alumina $0,05 \mu \mathrm{m}$. Após o polimento, as amostras foram lavadas em água e álcool, secas e armazenadas. Antes de serem introduzidas no dispositivo de nitretação, as amostras foram lavadas com tetracloroetileno em ultra-som durante 60 minutos, para eliminação de gorduras e outras impurezas superficiais.

Após serem colocadas no dispositivo de nitretação, as superfícies das amostras foram limpas utilizando-se o processo de pulverização catódica (sputtering) com argônio, sob uma pressão de $500 \mathrm{~Pa}$, a uma temperatura $50^{\circ} \mathrm{C}$ menor que a temperatura de nitretação a plasma, por 60 minutos. Para o processo de nitretação a plasma, realizado em um reator de fonte de alta tensão pulsada, utilizou-se uma mistura gasosa constante de $80 \%$ vol $_{2}$ e $20 \%$ vol $\mathrm{N}_{2}$, pressão de $500 \mathrm{~Pa}$, temperaturas de nitretação de $500^{\circ} \mathrm{C}, 540^{\circ} \mathrm{C}$ e $580^{\circ} \mathrm{C}$ e períodos de tratamento de 3 e 5 horas. As medidas das temperaturas foram feitas por meio de um termopar inserido em um corpo cilíndrico no porta-amostra ${ }^{(14)}$.

Para a avaliação do desgaste, utilizou-se um dispositivo de microdesgaste com esfera presa, carga de $2,45 \mathrm{~N}$, rotação de 300rpm, esfera de diâmetro de uma polegada, material da esfera SAE52100 temperada (dureza de 800HV), teste à temperatura ambiente, com tempos de teste de 5, 10, 20 e 30 minutos, sem o uso de óleo lubrificante ${ }^{(14)}$. Para cada condição de teste, ou seja, para cada condição de nitretação e tempo de teste, utilizou-se uma esfera diferente, produzindose uma calota de desgaste em cada amostra. A Equação $1^{(15)}$ foi utilizada para o cálculo do volume de desgaste.

$V=\pi \cdot \frac{b^{4}}{64 \cdot R^{2}} \cdot\left(R-\frac{b^{2}}{8 \cdot R}\right) \approx \frac{\pi \cdot b^{4}}{64 \cdot R} \quad b \ll<R$

onde: $\mathrm{b}=$ diâmetro da calota; $\mathrm{R}=$ raio da esfera. 
Segundo Kassman et al. ${ }^{(16)}$, a profundidade da calota de desgaste pode ser calculada a partir do volume de desgaste, através da Equação 2.

$$
V_{s}=\frac{\pi}{3} \cdot h_{S}^{2} \cdot\left(3 \cdot r-h_{S}\right)
$$

onde: $\mathrm{V}_{\mathrm{s}}=$ volume de desgaste; $\mathrm{h}_{\mathrm{s}}=$ profundidade da calota; $r=$ raio da esfera.

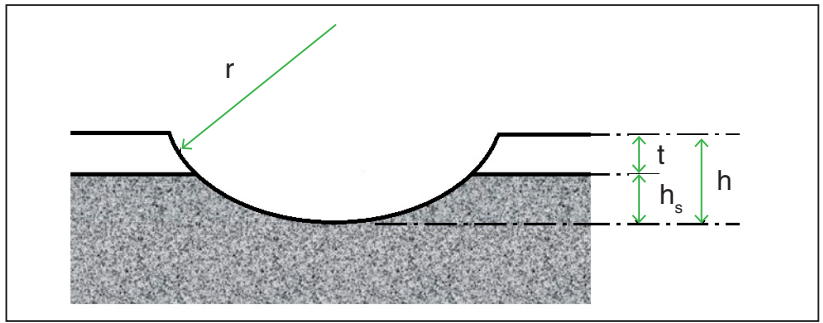

Figura 1: Geometria da calota de desgaste ${ }^{(16)}$.

Desta forma, podem-se comparar os valores de profundidade encontrados para cada condição de teste, com os valores das espessuras das camadas nitretadas nas seções transversais das amostras, verificando se as camadas foram ou não rompidas.

Para a análise da microdureza, as medidas foram obtidas na escala Vickers (HV) em um durômetro BUEHLER com carga de 100 gf. Os valores de microdureza foram obtidos somente na região da superfície das amostras, uma vez que as espessuras das camadas nitretadas formadas foram bem pequenas. Para cada amostra, foram realizadas 12 medições em pontos distintos da superfície, de maneira aleatória, para possibilitar a avaliação da dispersão dos valores.

\section{RESULTADOS E DISCUSSÃO}

\section{Análise do Desgaste}

A Figura 2 apresenta as imagens das calotas de desgaste como resultado do teste de desgaste para todas as amostras avaliadas. Para cada calota de desgaste foram feitas oito medições de diâmetro, em oito posições diferentes, e como resultado calculouse o diâmetro médio da mesma. Com os resultados dos diâmetros médios, utilizou-se a Equação 1 para o cálculo do volume de desgaste, dado em milímetros cúbicos $\left(\mathrm{mm}^{3}\right)$. O resultado comparativo está apresentado no gráfico da Figura 3.

Nota-se, pela Figura 3, que as amostras nitretadas, independentemente das condições aplicadas, apresentaram melhores resistência ao desgaste ao final do teste de 30 minutos, em comparação com as amostras ferroxidadas e não tratadas (somente sinterizadas). As amostras nitretadas a 540 e $580^{\circ} \mathrm{C}$ por 5 horas apresentaram as melhores resistências ao desgaste, indicando que quanto maior o tempo e maior a temperatura de tratamento, melhor tal propriedade. No início do teste, o volume

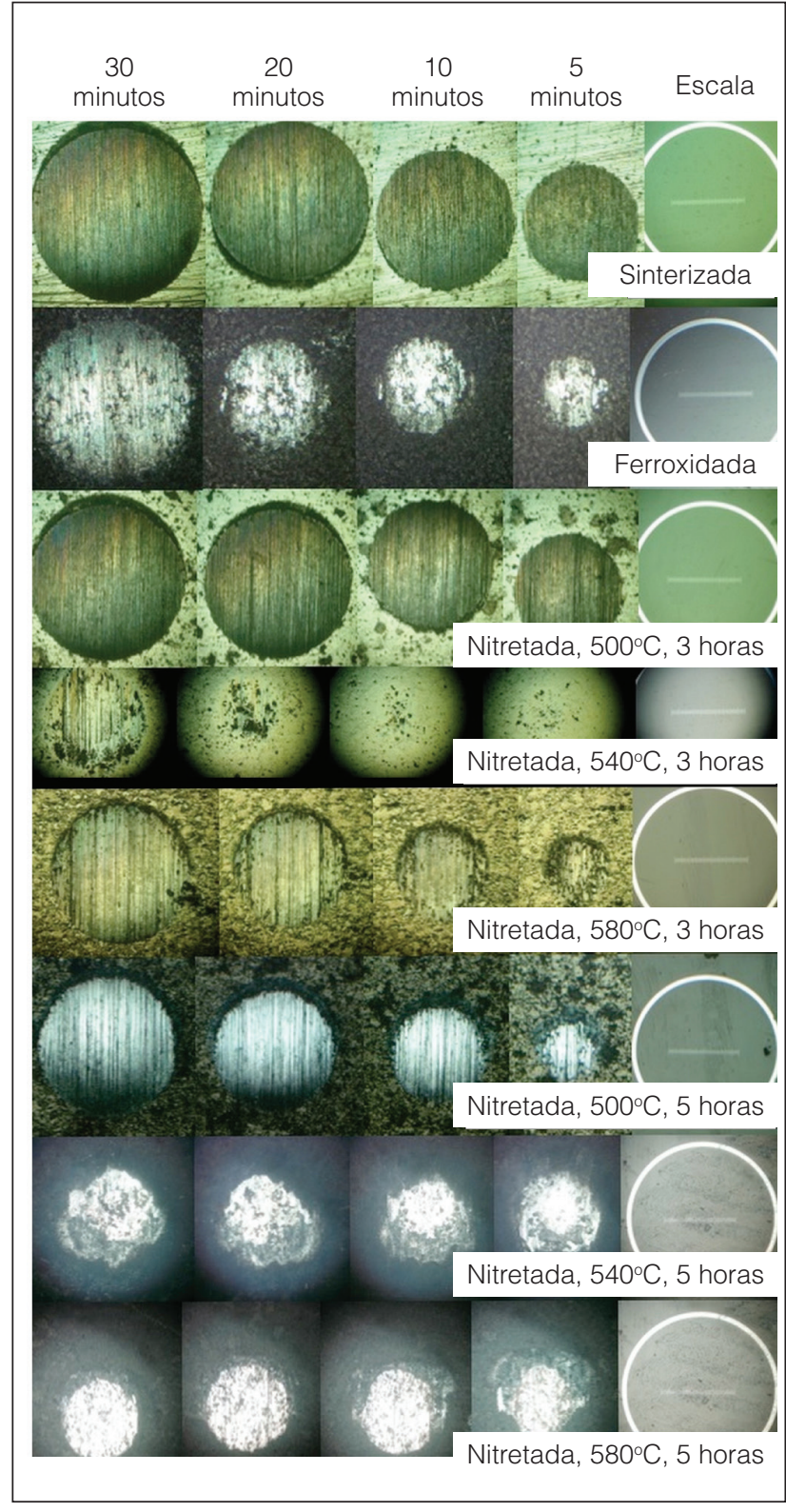

Figura 2: Calotas de desgaste das amostras após o teste $(30,20$, 10 e $5 \mathrm{~min}$ respectivamente). Escala de $1 \mathrm{~mm}$ utilizada para cada condição.

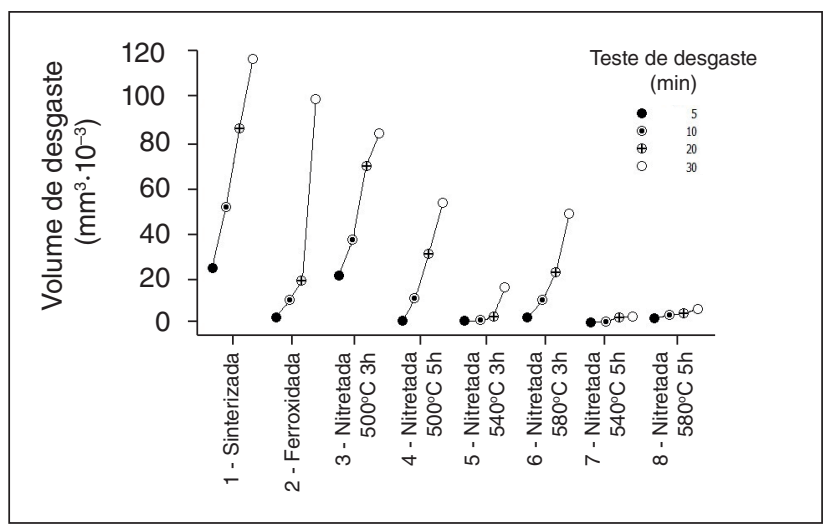

Figura 3: Volume de desgaste em função das condições de nitretação e do tempo de teste. 
de desgaste foi bem próximo para todas as amostras, enquanto que no final (após 30 minutos de ensaio), o desgaste para as amostras nitretadas foi menor.

Na Figura 4 verifica-se que as amostras nitretadas por 5 horas possuem melhor resistência ao desgaste que as amostras nitretadas por 3 horas, para uma dada temperatura.

A amostra ferroxidada também apresentou boa resistência ao desgaste, porém devido à pequena espessura da camada ferroxidada (em torno de 3,5 micrometros), o desgaste após os 30 minutos de teste foi mais elevado do que todas as amostras nitretadas.

Particularmente para a amostra nitretada a $540^{\circ} \mathrm{C}$ durante 5 horas, o valor do volume de desgaste no final do teste de 30 minutos foi cerca de 45 vezes inferior ao da amostra sinterizada, e aproximadamente 35 vezes inferior ao da amostra ferroxidada.

Compararam-se, para cada condição de nitretação e diferentes tempos de testes, os valores da profundidade da calota de desgaste obtidas pelo uso da Equação 2, com a profundidade das camadas nitretadas, obtidas nas micrografias da seção transversal das

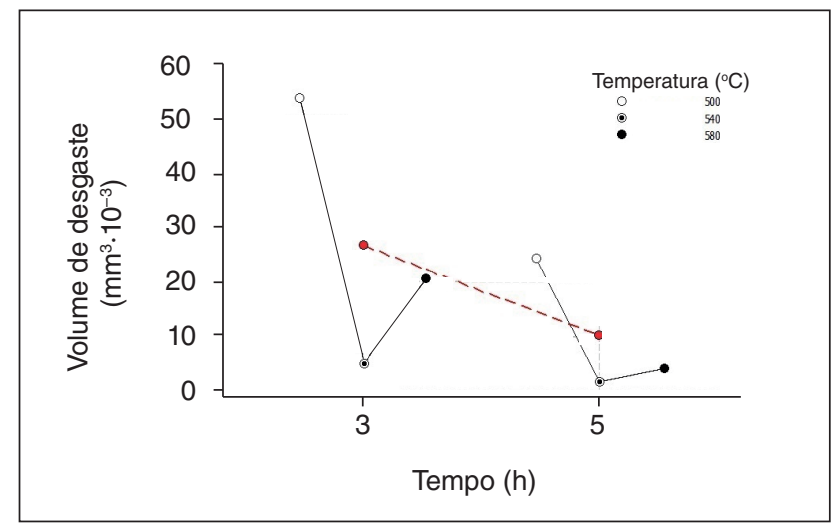

Figura 4: Volume de desgaste em função da temperatura e do tempo de nitretação. amostras, apresentadas no artigo recentemente publicado por esta revista $^{(13)}$. Os resultados estão apresentados na Tabela 2.

Nota-se pela Tabela 2 que a condição de nitretação em $540^{\circ} \mathrm{C}$ durante 5 horas, promoveu uma espessura de camada nitretada maior que a profundidade da calota de desgaste para todos os tempos de teste. Para amostras nitretadas em baixa temperatura $\left(500^{\circ} \mathrm{C}\right)$, a profundidade da calota de desgaste calculada para os 5 minutos de teste foi maior que a espessura da camada nitretada, indicando que a camada nitretada foi rompida logo nos 5 minutos iniciais do ensaio.

\section{Análise da Microdureza}

$\mathrm{Na}$ Figura 5 apresentam-se os resultados dos testes de microdurezas superficiais. Os maiores valores de microdurezas foram observados para as amostras nitretadas a $580^{\circ} \mathrm{C}$ por $3 \mathrm{e}$ 5 horas (valores médios de microdurezas superficiais de $286 \mathrm{HV}$ e $319 \mathrm{HV}$ respectivamente). Há uma tendência no aumento dos valores de microdureza quando se aumenta a temperatura de tratamento, para os mesmos tempos de nitretação. Tanto para as amostras nitretadas por 3 ou 5 horas, os maiores valores de microdurezas superficiais foram obtidos para as amostras

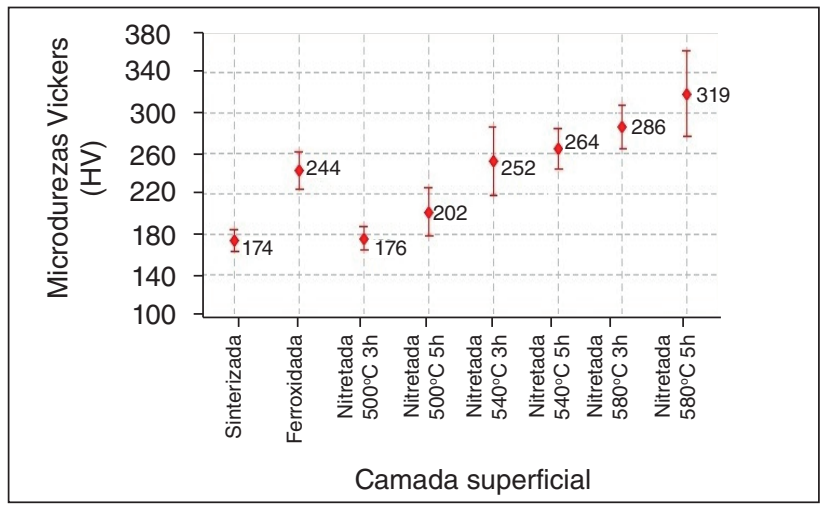

Figura 5: Valores de microdurezas Vickers (HV).

Tabela 2: Comparação da espessura da camada nitretada e profundidade da calota de desgaste.

\begin{tabular}{|c|c|c|c|c|c|c|c|c|c|}
\hline \multirow[b]{2}{*}{ Tratamento } & \multirow{2}{*}{$\begin{array}{l}\text { Profundidade } \\
\text { da camada } \\
\text { nitretada }(\mathrm{mm})\end{array}$} & \multicolumn{2}{|c|}{$5 \mathrm{~min}$} & \multicolumn{2}{|c|}{$10 \mathrm{~min}$} & \multicolumn{2}{|c|}{$20 \mathrm{~min}$} & \multicolumn{2}{|c|}{$30 \mathrm{~min}$} \\
\hline & & $\begin{array}{c}\text { Volume de } \\
\text { desgaste } \\
\left(\mathrm{mm}^{3}\right)\end{array}$ & $\begin{array}{c}\text { Valor hs } \\
(\mu \mathrm{m})\end{array}$ & $\begin{array}{c}\text { Volume de } \\
\text { desgaste } \\
\left(\mathrm{mm}^{3}\right)\end{array}$ & $\begin{array}{c}\text { Valor hs } \\
\quad(\mu \mathrm{m})\end{array}$ & $\begin{array}{c}\text { Volume de } \\
\text { desgaste } \\
\left(\mathrm{mm}^{3}\right)\end{array}$ & $\begin{array}{c}\text { Valor hs } \\
\quad(\mu \mathrm{m})\end{array}$ & $\begin{array}{c}\text { Volume de } \\
\text { desgaste } \\
\left(\mathrm{mm}^{3}\right)\end{array}$ & $\begin{array}{c}\text { Valor hs } \\
\quad(\mu \mathrm{m})\end{array}$ \\
\hline Ferrox & 3.57 & 0.0030 & 8.67 & 0.0106 & 16.30 & 0.0192 & 21.95 & 0.0995 & 49.98 \\
\hline $\begin{array}{l}\text { Nitretada } \\
500^{\circ} \mathrm{C}-3 \mathrm{~h}\end{array}$ & 4.63 & 0.0220 & 23.49 & 0.0368 & 30.39 & 0.0701 & 41.94 & 0.0843 & 45.99 \\
\hline $\begin{array}{l}\text { Nitretada } \\
540^{\circ} \mathrm{C}-3 \mathrm{~h}\end{array}$ & 8.33 & 0.0010 & 5.01 & 0.0014 & 5.92 & 0.0029 & 8.53 & 0.0160 & 20.03 \\
\hline $\begin{array}{l}\text { Nitretada } \\
580^{\circ} \mathrm{C}-3 \mathrm{~h}\end{array}$ & 8.64 & 0.0030 & 8.67 & 0.0100 & 15.84 & 0.0222 & 23.59 & 0.0487 & 34.96 \\
\hline $\begin{array}{l}\text { Nitretada } \\
500^{\circ} \mathrm{C}-5 \mathrm{~h}\end{array}$ & 5.19 & 0.0011 & 5.26 & 0.0110 & 16.61 & 0.0312 & 27.98 & 0.0533 & 36.57 \\
\hline $\begin{array}{l}\text { Nitretada } \\
540^{\circ} \mathrm{C}-5 \mathrm{~h}\end{array}$ & 11.11 & 0.0004 & 3.18 & 0.0009 & 4.74 & 0.0028 & 8.38 & 0.0028 & 8.38 \\
\hline $\begin{array}{l}\text { Nitretada } \\
580^{\circ} \mathrm{C}-5 \mathrm{~h}\end{array}$ & 9.82 & 0.0021 & 7.26 & 0.0042 & 10.26 & 0.0045 & 10.62 & 0.0061 & 12.37 \\
\hline
\end{tabular}


nitretadas a $580^{\circ} \mathrm{C}$, e os menores valores para as amostras tratadas a $500^{\circ} \mathrm{C}$. Verifica-se que a seleção da temperatura para o processo de nitretação de ligas ferrosas influencia diretamente nos resultados da microdureza superficial.

As amostras sinterizada e ferroxidada apresentaram valores médios de microdurezas em torno de $174 \mathrm{HV}$ e $244 \mathrm{HV}$, e os baixos valores de microdureza para amostras nitretadas a $500^{\circ} \mathrm{C}$ são explicados pela ineficiência do processo de nitretação a esta temperatura, que provavelmente não causou a formação significativa de nitretos de ferro na camada modificada. O valor médio de microdureza nesta mesma temperatura foi bem próximo ao valor médio encontrado na amostra sem tratamento algum (aproximadamente 175HV). O maior endurecimento foi obtido por um tratamento de 5 horas. A difusão de nitrogênio a baixas temperaturas é lenta, mas para o tratamento de 5 horas, o nitrogênio teve tempo suficiente para se difundir na liga e, consequentemente, aumentar a dureza superficial.

\section{CONCLUSÕES}

De um modo geral, as amostras nitretadas apresentaram melhores desempenhos quanto aos níveis de desgaste e microdureza, quando comparadas com as amostras da liga sem tratamento e amostras submetidas ao tratamento de ferroxidação. A melhoria na resistência ao desgaste e o aumento na dureza superficial podem ser explicados pela presença da camada superficial composta por nitretos de ferro que foi formada durante o processo de nitretação a plasma.

Dentre as diversas condições de nitretação aplicadas, os melhores desempenhos quanto ao nível de desgaste foram obtidos para as amostras tratadas durante 5 horas nas temperaturas de 540 e $580^{\circ} \mathrm{C}$.

Especificamente para amostras nitretadas em $540^{\circ} \mathrm{C}$ durante 5 horas, a profundidade da calota de desgaste foi menor que a espessura da camada nitretada, indicando que nesta condição de tratamento, não houve o rompimento da camada nitretada mesmo após 30 minutos de teste.

Resultados de microdureza mostraram valores médios próximos para as amostras nitretadas durante 3 e 5 horas, indicando que os tempos de tratamentos tiveram pequena influência nas microdurezas superficiais. As menores durezas das camadas obtidas a $500^{\circ} \mathrm{C}$ podem ser devidas as menores espessuras das mesmas, o que pode ter permitido que o substrato tenha contribuído também para com essas durezas.

As variáveis tempo e temperatura de nitretação influenciam na determinação dos níveis de desgaste e microdureza das amostras, porém a variável temperatura tem maior significância.

\section{AGRADECIMENTOS}

Os autores agradecem ao $\mathrm{CNPq}$ e à FAPESP.

\section{REFERÊNCIAS}

1. FERNANDES F. A. P.; LOMBARDI NETO, A.; CASTELETTI, L. C. OLIVEIRA A. M.; TOTTEN, G. E., Heat Treat. Prog. 8 (2008) 41.

2. MICHEL, H.; CZERWIEC, T.; GANTOIS, M.; ABLITZER, D. RICARD, A., Surf. Coat. Technol. 72 (1995) 103.

3. BORGIOLI, F.; FOSSATI, A.; GALVANETTO, E.; BACCI, T., Surf Coat Technol. 200 (2005) 2474

4. KLIALGA, A. M.; POHL, M., Surf. Coat. Technol. 98 (1998) 1205.

5. GRUN, R.; GUNTHER, H. J., Mater. Sci. Eng. A 140 (1991) 435

6. INAL, O. T.; ROBINO, C. V., Thin Solid Films 95 (1982) 195

7. SPALVIS, T., Thin Solid Films 108 (1983) 157

8. ROBINO, C. V.; INAL, O. T., Mater. Sci. Eng. 59 (1983) 79.

9. GENEL, K.; DEMIRKOL, M.; ÇAPA, M., Mater. Sci. Eng. A 279 (2000) 207.

10. CHO, K. S.; LEE C. O., J. Eng. Mater. Technol. 102 (1980) 229.

11. MALISKA, A. M.; DE OLIVEIRA, A. M.; KLEIN, A. N.; MUZART, J. L. R., Surf. Coat. Technol. 141 (2001) 128.

12. COSTA, J. P.; FERREIRA, J. M.; RAMALHO, A. L., Theor. Appl. Fract. Mech. 35 (2001) 69

13. FONTES, M. A.; PEREIRA, R. G.; CASTELETTI, L. C.; NASCENTE, P. A. P., Rev. Bras. Aplic. Vácuo 34 (2015) 54

14. FERNANDES, F. A. P.; HECK, S. C.; PEREIRA, R. G.; PICON, C A.; NASCENTE, P. A. P.; CASTELETTI, L. C., Surf. Coat. Technol. 204 (2010) 3087.

15. RUTHERFORD, K.L.; HUTCHINGS, I.M., Surf. Coat. Technol. 79 (1996) 231-239.

16. KASSMAN, $\AA$; JACOBSON, S.; ERICKSON, L.; HEDENQVIST, P.; OLSSON, M., Surf. and Coat. Technol. 50 (1991) 75-84. 